\title{
Contribution to the knowledge of the Neotropical Anteoninae (Hymenoptera, Dryinidae), with the descriptions of two new species and new records
}

\author{
André Luis Martins ${ }^{1,3} \&$ Massimo $01 \mathrm{lmi}^{2,4}$ \\ 1 Universidade Federal do Paraná (UFPR), Setor de Ciências Biológicas, Departamento de Zoologia (DZ00), \\ Laboratório de Biologia Comparada de Hymenoptera (LBCH). Curitiba, PR, Brasil. \\ 2 Tropical Entomology Research Center. Viterbo, Italy. \\ 3 ORCID: http://orcid.org/0000-0002-4794-0644. E-mail: andrelm3048@gmail.com \\ ${ }^{4}$ ORCID: http://orcid.org/0000-0001-5953-5075. E-mail: olmimassimo@gmail.com
}

\begin{abstract}
Two new species of Anteoninae (Hymenoptera, Chrysidoidea, Dryinidae) are described: Deinodryinus brasiliensis sp. nov., from Brazil (Bahia, Minas Gerais and Paraná) and D. mexicanus sp. nov., from Mexico (Chiapas). Comments on Lonchodryinus tricolor Kieffer, 1905 are presented and new geographic records are provided for the Brazilian states of Minas Gerais and Paraná. The key to the females of the Neotropical Deinodryinus is updated, and illustrations and distributional maps are provided for the species studied here.
\end{abstract}

Keywords. Brazil; Chrysidoidea; Deinodryinus brasiliensis; Deinodryinus mexicanus; Lonchodryinus tricolor; Mexico; Pincer wasps.

\section{INTRODUCTION}

Dryinidae (Hymenoptera: Chrysidoidea) are cosmopolitan wasps, parasitoids and often also predators of leafhoppers, planthoppers and treehoppers (Hemiptera, Auchenorrhyncha) (Guglielmino et al., 2013; Martins et al., 2020). Known commonly as pincer wasps, they include 17 subfamilies (Olmi et al., 2019, 2020b) among which, Anteoninae, with 653 species described in the world (Martins et al., 2020; Olmi et al., 2019, 2020a).

Anteoninae include seven genera, four extant and three fossil (Olmi et al., 2019). The following four genera are present in the Neotropical region: Anteon Jurine, 1807, represented by 74 species, Deinodryinus Perkins, 1907, by 114 species, Lonchodryinus Kieffer, 1905, by two species and Metanteon Olmi, 1984, by one species (Olmi \& Virla, 2014). The genera Anteon and Deinodryinus are the most speciose, with about 466 and 166 world species, respectively. The knowledge of the biology and hosts associated to Anteoninae is restricted to three genera, Anteon, Deinodryinus and Lonchodryinus, both associated with Cicadellidae.
For the Neotropical region, there are only records related to Anteon (Olmi \& Virla, 2014; Martins, 2015; Olmi et al., 2019, 2020a; Martins et al., 2020). In the Neotropical region, the genus Deinodryinus includes 114 species, of which 38 species occurring in Brazil and 19 in Mexico (Olmi \& Virla, 2014; Martins, 2015; Martins et al., 2015). The genus Lonchodryinus includes two Neotropical species: L. neotropicus Olmi, 1991, occurring in Costa Rica, and L. tricolor, recorded from Argentina, Bolivia, Brazil and Paraguay. The genus Metanteon includes only one Neotropical species, occurring in Argentina and Chile: Metanteon aerias (Walker) (Olmi, 1984; Olmi \& Virla, 2014). Metanteon is a small transantarctic genus occurring only in the southern extremity of South America and New Caledonia and including only two species: $M$. aerias and $M$. poirieri Speranza, Olmi, Guglielmino, Capradossi \& Contarini, 2019 (Speranza et al., 2019).

In this paper we contribute to the knowledge of the Neotropical fauna of Anteoninae by describing two new species of Deinodryinus and reporting new distribution records of Lonchodryinus tricolor. 


\section{MATERIAL AND METHODS}

In this study, 37 specimens of Anteoninae, collected by Malaise and Light traps were examined, 10 belonging to Deinodryinus and 27 to Lonchodryinus. The specimens studied here are deposited in the following collections (curators between brackets):

- DZUP: Coleção Entomológica Pe. Jesus Santiago Moure, Universidade Federal do Paraná, Curitiba, Paraná, Brazil (Dr. Gabriel A.R. Melo);

- LRRP: Laboratório de Sistemática e Bioecologia de Parasitoides e Predadores, Ribeirão Preto, São Paulo, Brazil (Dr. Nelson W. Perioto);

- MNHN: Muséum National d'Histoire Naturelle, Paris, France (Dr. Claire Villemant);

- UEFS: Universidade Estadual de Feira de Santana, Feira de Santana, Bahia, Brazil (Dr. Freddy B. Quijano and Dr. Sérgio Andena);

- ZSJRP: Coleção de Hymenoptera do Departamento de Zoologia do Instituto de Biociências, Letras e Ciências Exatas - UNESP, São José do Rio Preto, São Paulo, Brazil (Dr. Fernando B. Noll).

The specimens of Deinodryinus and Lonchodryinus were identified by the keys of Olmi \& Virla (2014). The terminology adopted here follows mainly Olmi et al. (2019), except for the propodeum (following Olmi \& Virla (2014) and the fore wing venation (following Brothers (2011). The holotype of Lonchodryinus tricolor deposited at MNHN was examined personally by $\mathrm{MO}$ and through photographs by ALM.

In the descriptions, the following abbreviations are used: POL, refers to the minimum distance between the inner edges of the lateral ocelli; $\mathbf{O L}$, refers to the minimum distance between the inner edges of the lateral ocellus and the median ocellus; $\mathbf{O O L}$, refers to the minimum distance from the outer edge of a lateral ocellus to the eye inner margin; OPL, refers to the minimum distance from the posterior edge of a lateral ocellus to the occipital carina; $\mathbf{T L}$, refers to the minimum distance from the posterior edge of an eye to the occipital carina.

Label information was transcribed as follows: a backslash $(\backslash)$ indicates different lines on the label and two quotation marks (" ") indicate different labels of the same specimen.

Colour images were obtained using a LEICA DFC295 digital camera attached to the stereoscopic microscope and processed with Zerene Stacker software (1.04 version build). Scanning electron photomicrographs (SEM VEGA3 TESCAN) were made in the Center of Electron Microscopy of the Universidade Federal do Paraná. Figures were prepared using Adobe Photoshop (version 11.0).

Geographical coordinates not indicated in the labels were obtained using Google Earth 4.0 software. The distribution maps were created using SimpleMappr (Shorthouse, 2010).

\section{RESULTS AND DISCUSSION}

\author{
Taxonomy \\ Genus Deinodryinus Perkins, 1907 \\ Deinodryinus brasiliensis sp. nov. \\ (Figs. 1A-F, 3A, C, 5D, 6)
}

Diagnosis: Female with head (Fig. 1C) mostly rugose; mesosoma (Fig. 1A) mostly black; fore wing (Fig. 3A) completely darkened; notauli (Fig. 1D) almost reaching posterior margin of mesoscutum; $5^{\text {th }}$ protarsomere (Figs. 3C, 5D) with medial notch and distal region short.

Description: Female (Fig. 1A): Fully winged; body length 7.0-7.2 mm (holotype $7.0 \mathrm{~mm}$ ). Color: Head (Figs. 1A-C) black, except lower area of face (Fig. 1B) yellow-whitish; mandible yellow-whitish, except teeth darkened; antenna (Fig. 1A) testaceous, except ventral margin of scape yellow-whitish and flagellomeres 5-8 darkened; pronotum (Figs. 1D-E) black, except lateral surfaces and posterior margin testaceous; rest of mesosoma black; fore wing (Fig. 3A) completely darkened; legs (Fig. 1A) testaceous; petiole testaceous; metasoma black, except first tergum, last tergum, and last sternum testaceous. Pubescence: Head (Figs. 1B-C) with fine, short and sparse pilosity, except clypeus (Fig. 1B) with pilosity longer than that of rest of head; pronotum (Fig. 1D) with fine and short pilosity; mesoscutum, mesoscutellum and metanotum (Figs. 1D-E) with fine and sparse pilosity; mesopleuron, metapleuron and legs (Figs. 1A, E-F) with fine and short pilosity; propodeum with fine and erect pilosity. Integumental sculpture: Head (Figs. 1B-C) rugose, except gena and vertex near ocellus with coarse punctures; occipital carina (Fig. 1C) complete; frontal line (Fig. 1B) absent; pronotum (Figs. 1D-E) rugose, except disc smooth, with fine and sparse punctures, and anterior collar with several narrow carinae; mesoscutum (Fig. 1D) finely and sparsely punctate, smooth among punctures; notauli (Fig. 1D) incomplete, almost reaching posterior margin of mesoscutum; mesoscutellum (Fig. 1D) finely punctate, unsculptured among punctures, with anterior wide groove composed of about five foveas; metanotum unsculptured; mesopleuron (Fig. 1E) punctate, unsculptured among punctures; metapleuron (Fig. 1E) rugose with many transverse carinae; propodeum (Fig. 1F) reticulate rugose. Structures and Proportions: Ocellar ratio: $\mathrm{OL}=6 ; \mathrm{POL}=10 ; \mathrm{OOL}=30$; $\mathrm{OPL}=33 ; \mathrm{TL}=28$. Antennomeres in following proportions: $50: 23: 63: 47: 42: 40: 33: 32: 30: 35$. Protarsomeres in following proportions: 43:10:20:50:90. Enlarged claw slightly shorter than $5^{\text {th }}$ protarsomere $(85: 90) ; 5^{\text {th }}$ protarsomere (Figs. 3C, 5D) with medial notch and distal region short. Claw of midle and posterior legs with basal expansion very development. Stigmal vein of fore wing (Fig. 3A) with distal part (3Rs\&4Rs) slightly longer than proximal part (2r-rs) (60:55). Dorsal surface of propodeum shorter than posterior surface (50:75). Tibial spurs 1:1:2.

Male: Unknown. 
Distribution: Deinodryinus brasiliensis sp. nov. is known only by five females collected in Brazil (Bahia, Minas Gerais and Paraná) (Fig. 6).

Type material: Brazil, Paraná: Holotype: + , Brasil, Paraná, Piraquara, Mananciais \da Serra, 16.xii.2006\G. Melo \& J.
Rafael $\backslash$ arm. luminosa (DZUP). Paratypes: Bahia: 3 \%, "Brasil, Bahia, 6kma\SE de Encruzilhada\ $15.567^{\circ} \mathrm{S} 40.869^{\circ} \mathrm{W}$ 910 m, 16.xii.2012\ G. Melo \& P. Grossi" "Armadilha\luminosa" (DZUP). Minas Gerais: 1 \%, "Brasil, MG, Berizal, Fazl Veredão, 14.xii.2007, $850 \mathrm{~m} \backslash 15^{\circ} 39^{\prime} 53^{\prime \prime}$ S 41 ${ }^{\circ} 39^{\prime} 56^{\prime \prime}$ W Grossi, Rafael \& Parizotto"'Armadilha\luminosa" (DZUP).
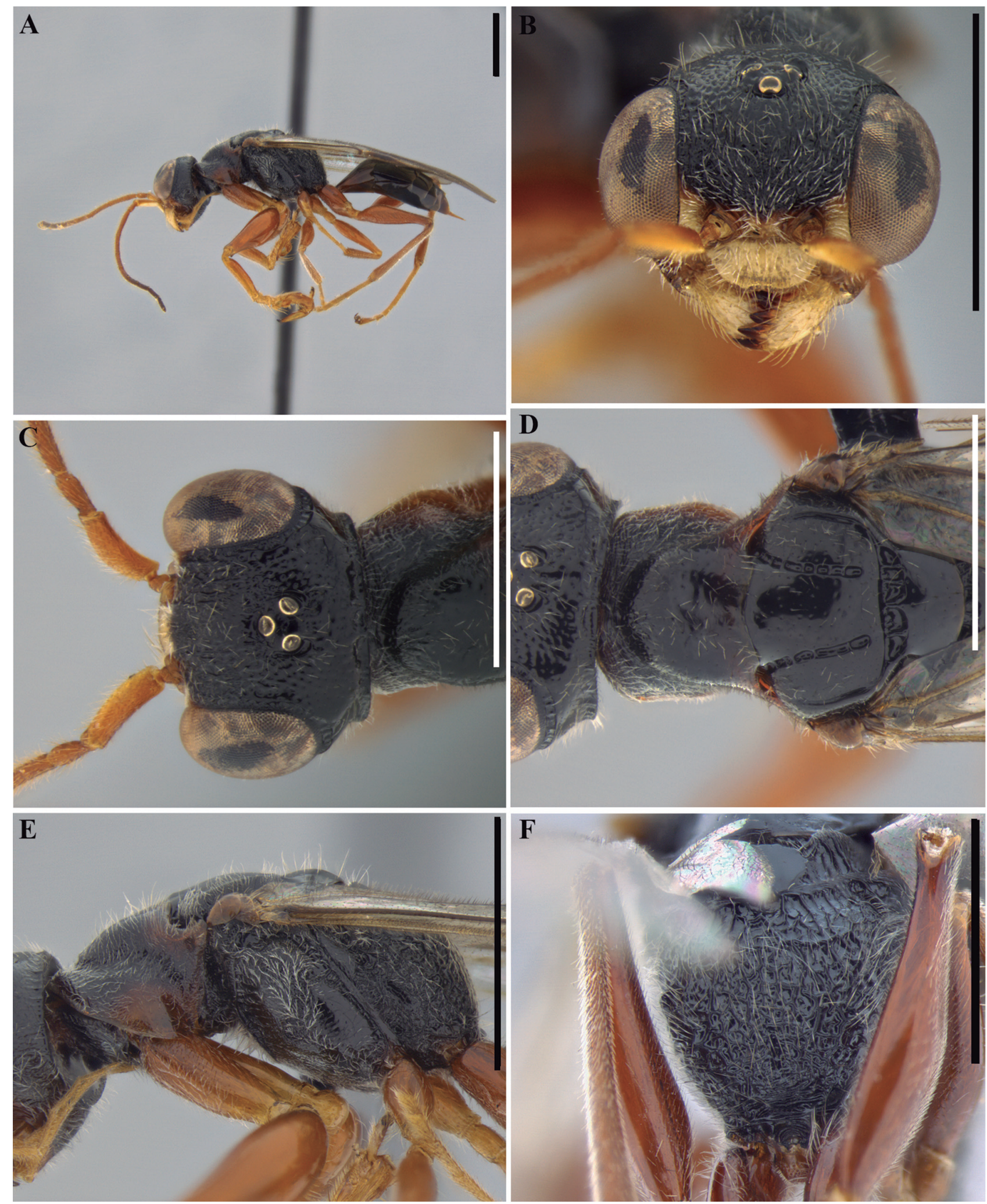

Figure 1. Deinodryinus brasiliensis sp. nov. (A) Habitus, lateral view; (B) Head, frontal view; (C) Head, dorsal view; (D) Pronotum, mesoscutum and mesoscutellum, dorsal view; (E) Mesosoma, lateral view; (F) Propodeum, posterior view. Scale bars: $1.0 \mathrm{~mm}$. 
Etymology: The name D. brasiliensis sp. nov. is a Latinized word meaning 'from Brazil', where the species was collected.

Remarks: Among the species of Deinodryinus from the Neotropical region, D. brasiliensis sp. nov. is similar to D. minor Olmi 1984. They share head more or less rugose; notauli almost reaching posterior margin of mesoscutum and $5^{\text {th }}$ protarsomere with medial notch and distal region short not forming right angle.

Following the description of $D$. brasiliensis sp. nov., the key to the females of the Neotropical Deinodryinus
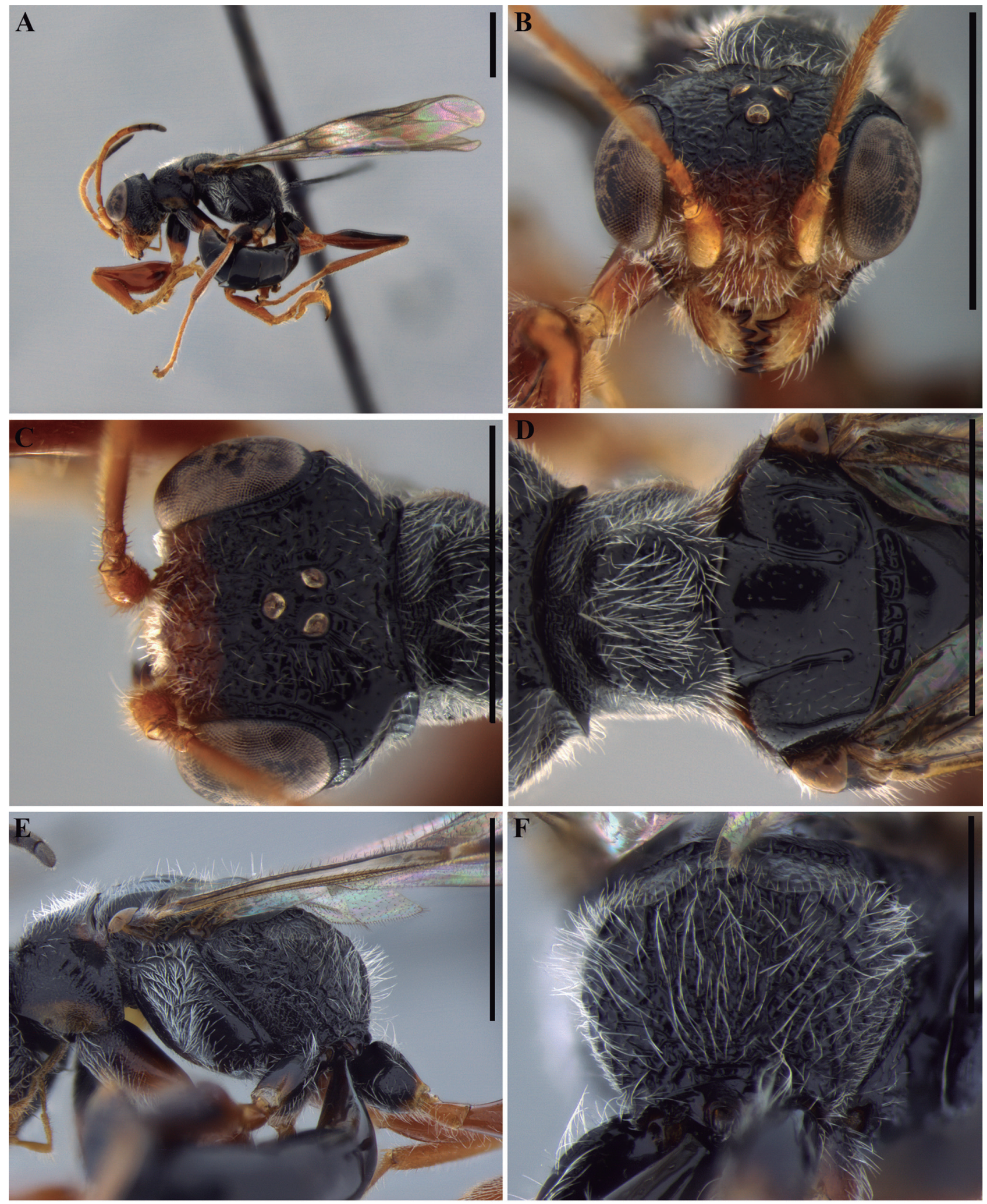

Figure 2. Deinodryinus mexicanus sp. nov. (A) Habitus, lateral view; (B) Head, frontal view; (C) Head, dorsal view; (D) Pronotum, mesoscutum and mesoscutellum, dorsal view; (E) Mesosoma, lateral view; (F) Propodeum, posterior view. Scale bars: (A-E) $1.0 \mathrm{~mm}$ (F) $0.5 \mathrm{~mm}$. 
published by Olmi \& Virla (2014) should be modified by replacing couplet 15 as follows:

15 Notauli almost reaching posterior margin of mesoscutum (Fig. 1D) ....15'

- Notauli reaching approximately $0.6-0.7 \times$ length of mesoscutum ....... 16

$15^{\prime}$ Fore wing hyaline, not darkened; mesosoma mostly testaceous; $5^{\text {th }}$ protarsomere without medial notch (Fig. 64A in OImi \& Virla, 2014) .......

D. minor $01 \mathrm{mi}$

- Fore wing completely darkened (Fig. 3A); mesosoma mostly black (Fig. 1A); $5^{\text {th }}$ protarsomere with medial notch (Figs. 3C, 5D)

D. brasiliensis sp. nov.

\section{Deinodryinus mexicanus sp. nov. \\ (Figs. 2A-F, 3B, D, 4C, 5, 6)}

Diagnosis: Female with first flagellomere longer than scape (Fig. 2B); head (Fig. 2A-C) mostly black, reticulate rugose; posterior surface of pronotum (Fig. 2D) less than twice as broad as long, punctate, unsculptured among punctures; notauli reaching about $0.8 \times$ length of mesoscutum (Fig. 2D); fore wing with two dark transverse bands (Fig. 3B); posterior surface of propodeum completely reticulate rugose (Figs. $2 \mathrm{E}-\mathrm{F}$ ); $5^{\text {th }}$ protarsomere with very short rows of lamellae situated only in the distal half (Figs. 3D, 5C) and with two very long distal lamella (Fig. 5C).

Description: Female (Fig. 2A): Fully winged; body length $7.6 \mathrm{~mm}$. Color: Head (Figs. 2A-B) black, except anterior half of frons and lower area of face testaceous; clypeus testaceous; lower genal area (Figs. 2A-B) with one narrow testaceous band; mandible testaceous, except teeth brown; antenna (Fig. 2A) testaceous, except flagellomeres 5-8 darkened; mesosoma (Fig. 2A, E) black, except lateral surface of pronotum (Figs. 2A, D) testaceous; fore wing (Fig. 3B) with two dark transverse bands; legs (Fig. 2A) red testaceous, except procoxa, mesocoxa, metacoxa and part of metafemur black; petiole black; metasoma black, except last tergum and sternum partially testaceous. Pubescence: Head (Fig. 2C) with fine and sparse pilosity, except part of face, clypeus and gena with short and dense pilosity; pronotum (Fig. 2D) with long and dense pilosity; mesoscutum, mesoscutellum and metanotum (Figs. 2D-E) with fine and sparse pilosity; legs (Fig. 2E) with fine and erect pilosity; mesopleuron (Fig. 2E) with fine and dense pilosity; metapleuron (Fig. 2E) with fine and
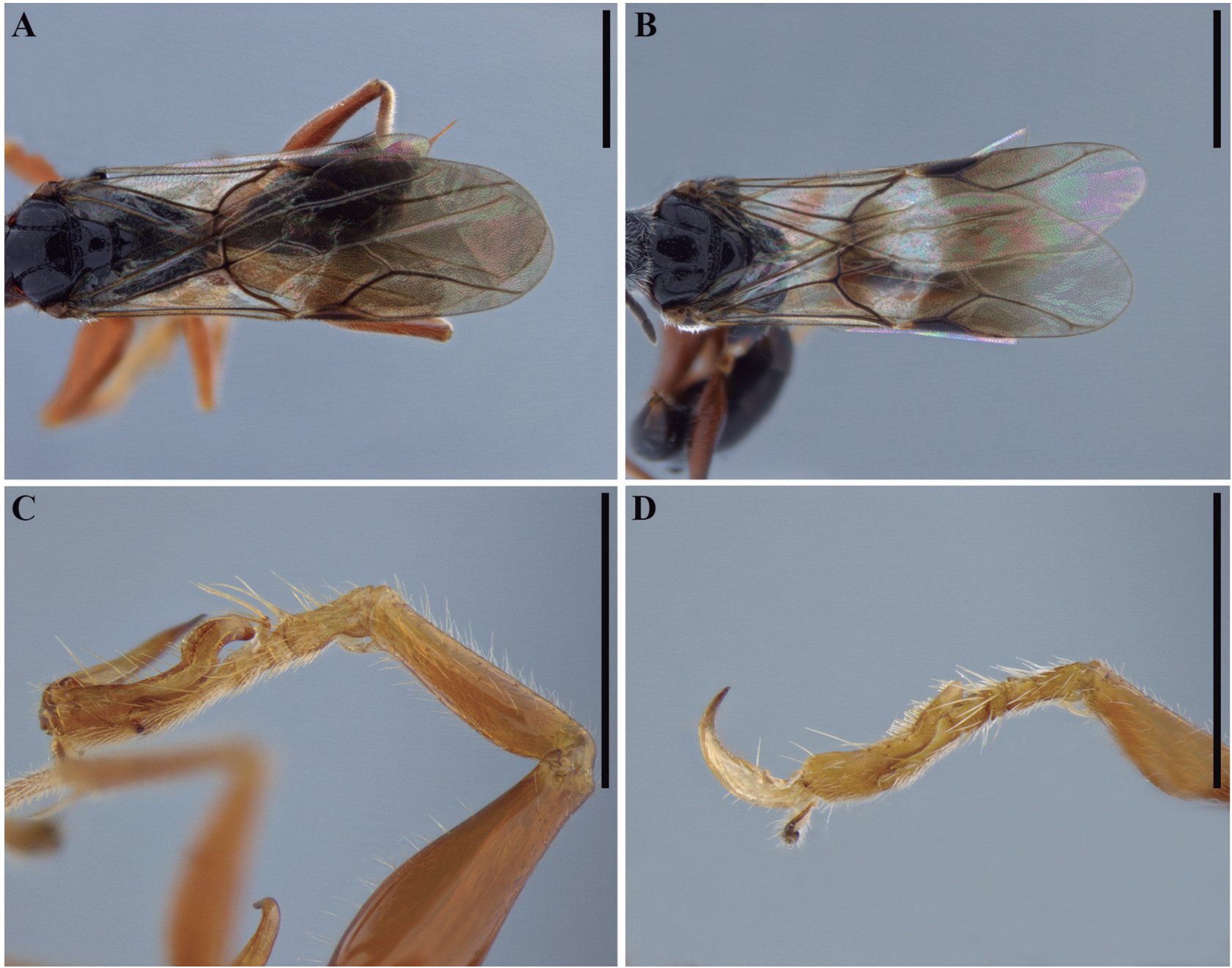

Figure 3. Fore wing and protarsus of holotypes of Deinodryinus species. (A, C) Deinodryinus brasiliensis sp. nov. (A, fore wing, $C$, fore tarsus); (B, D) Deinodryinus mexicanus sp. nov. (B, fore wing, $D$, fore tarsus). Scale bars: $1.0 \mathrm{~mm}$. 
short pilosity; propodeum (Fig. 2F) and metasoma with fine and erect pilosity. Integumental sculpture: Head (Figs. 2A, C) reticulate rugose, except irregular carinae near to ocellus; clypeus rugose (Fig. 2B); gena punctate, with surface rugose; vertex (Fig. $2 \mathrm{C}$ ) reticulate rugose, with rugosity less distinct than that of frons; occipital carina (Fig. 2C) complete; frontal line (Fig. 2B) absent; pronotum (Fig. 2D) with anterior collar rugose and disc sparsely punctate, smooth among punctures; mesoscutum (Fig. 2D) more sparsely punctate than disc of pronotum; notauli (Fig. 2D) incomplete, reaching about $0.8 \times$ length of mesoscutum; mesoscutel-
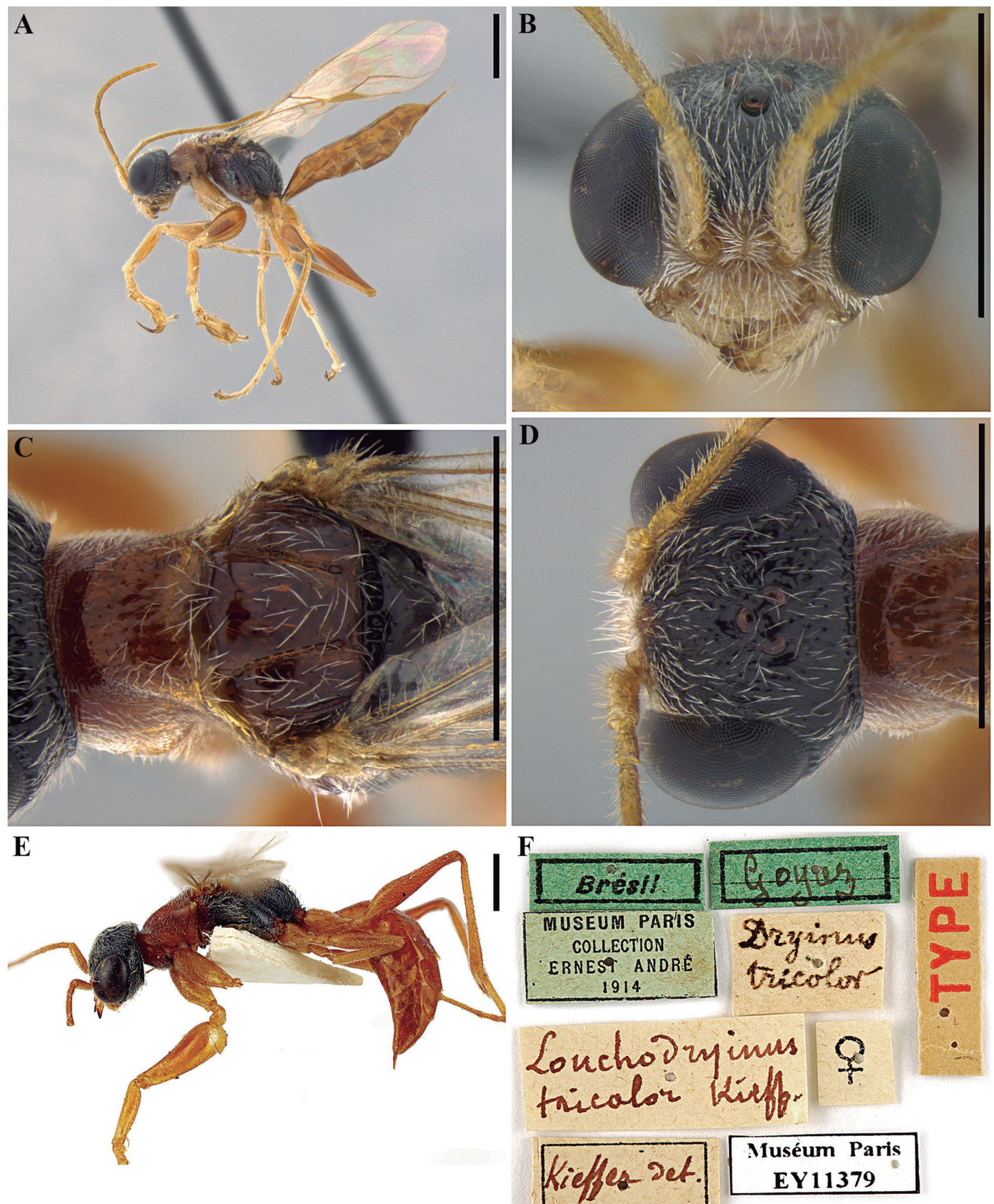

Figure 4. Lonchodryinus tricolor Kieffer. (A-D) Female from Brazil, Aracatu (BA): (A) Habitus, lateral view; (B) Head, frontal view; (C) Pronotum, mesoscutum and mesoscutellum, dorsal view; (D) Head, dorsal view. (E-F) Holotype (MNHN, EY 11379): (E) Habitus, lateral view; (F) Labels. Scale bars: 1.0 mm. 
lum (Fig. 2D) partially punctate, unsculptured among punctures; metanotum with central region unsculptured and lateral sides punctate; mesopleuron (Fig. 2C) rugose and partially punctate; metapleuron (Fig. 2C) rugose; propodeum reticulate rugose. Structures and Proportions: Ocellar ratio: $\mathrm{OL}=7 ; \mathrm{POL}=8 ; \mathrm{OOL}=35$; $\mathrm{OPL}=27 ; \mathrm{TL}=35$. Antennomeres in following proportions: 48:25:50:35:30:27:25:25:23:30. Protarsomeres in following proportions: 35:10:20:36:75. Enlarged claw slightly shorter than $5^{\text {th }}$ protarsomere (70:75), with inner proximal prominence bearing one long bristle; $5^{\text {th }}$ protarsomere (Figs. 3D, 5C) with very short rows of lamellae situated only in the distal half; apex with a set of lamellae, two of which very long. Claw of midle and posterior legs with basal expansion very devel- opment. Stigmal vein of fore wing (Fig. 3B) with distal part (3Rs\&4Rs) slightly longer than proximal part (2r-rs) (48:38). Dorsal surface of propodeum shorter than posterior surface (35:75). Tibial spurs 1:1:2.

Male: Unknown.

Distribution: Deinodryinus mexicanus sp. nov. is known only by two females collected in Mexico, Chiapas (Fig. 6).

Type material: Mexico: Holotype: $\$$, México, Chiapas, 4km\W de San Cristóbal, \Huiotepec, 2420 m, \ 13-19.

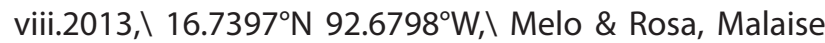
(DZUP). Paratype: Mexico: 1 , same data of holotype (DZUP).
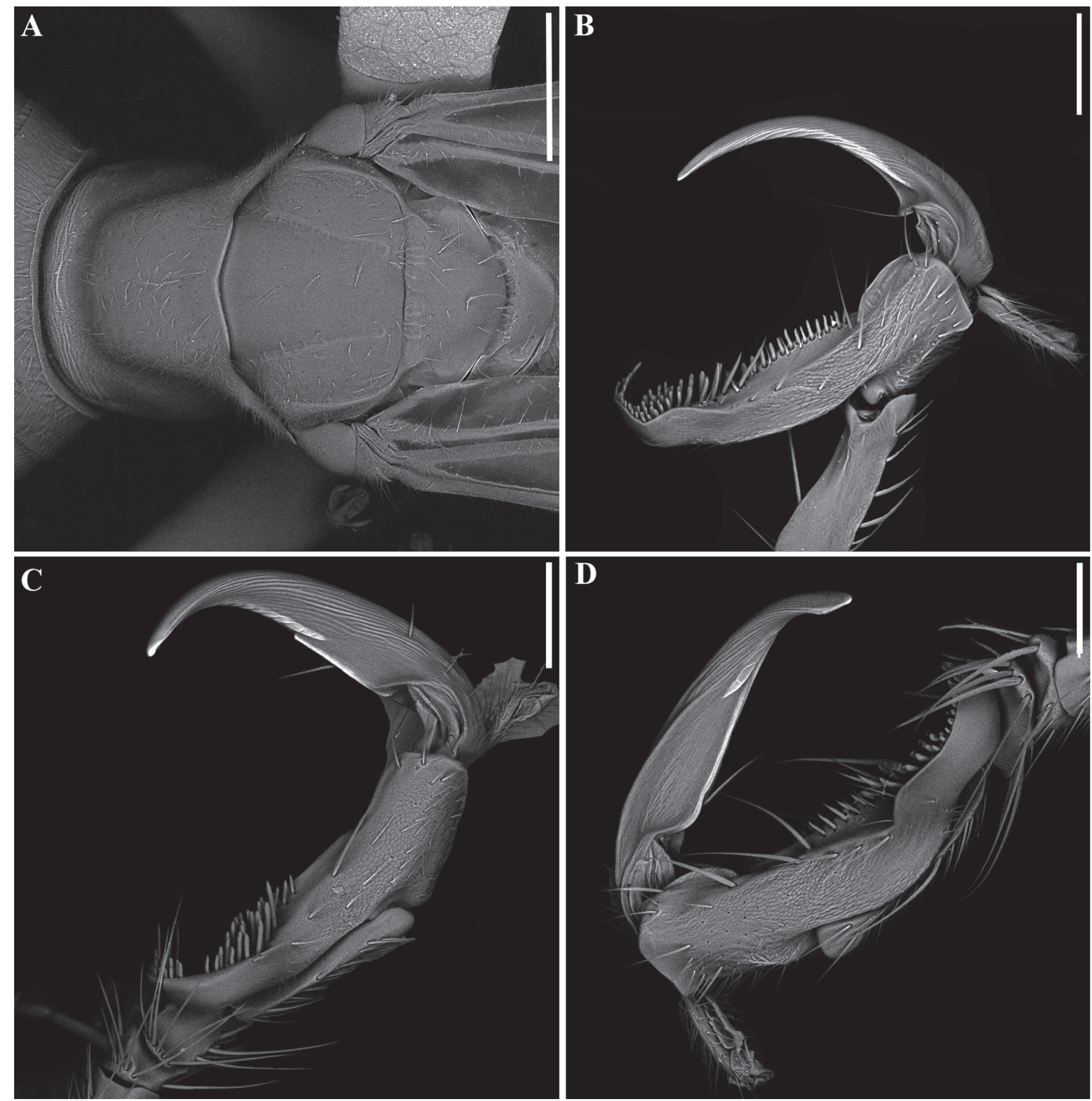

Figure 5. Eletromicrography of female species of Lonchodryinus Kieffer and Deinodryinus. (A-B) Lonchodryinus tricolor Brazil, Aracatu (BA): (A) Mesosoma (except propodeum), dorsal view; (B) Chela; (C) Chela, Deinodryinus mexicanus sp. nov.; (D) Chela, Deinodryinus brasiliensis sp. nov. Scale bars: (A) $500 \mu \mathrm{m}$; (B-D) $200 \mu \mathrm{m}$. 


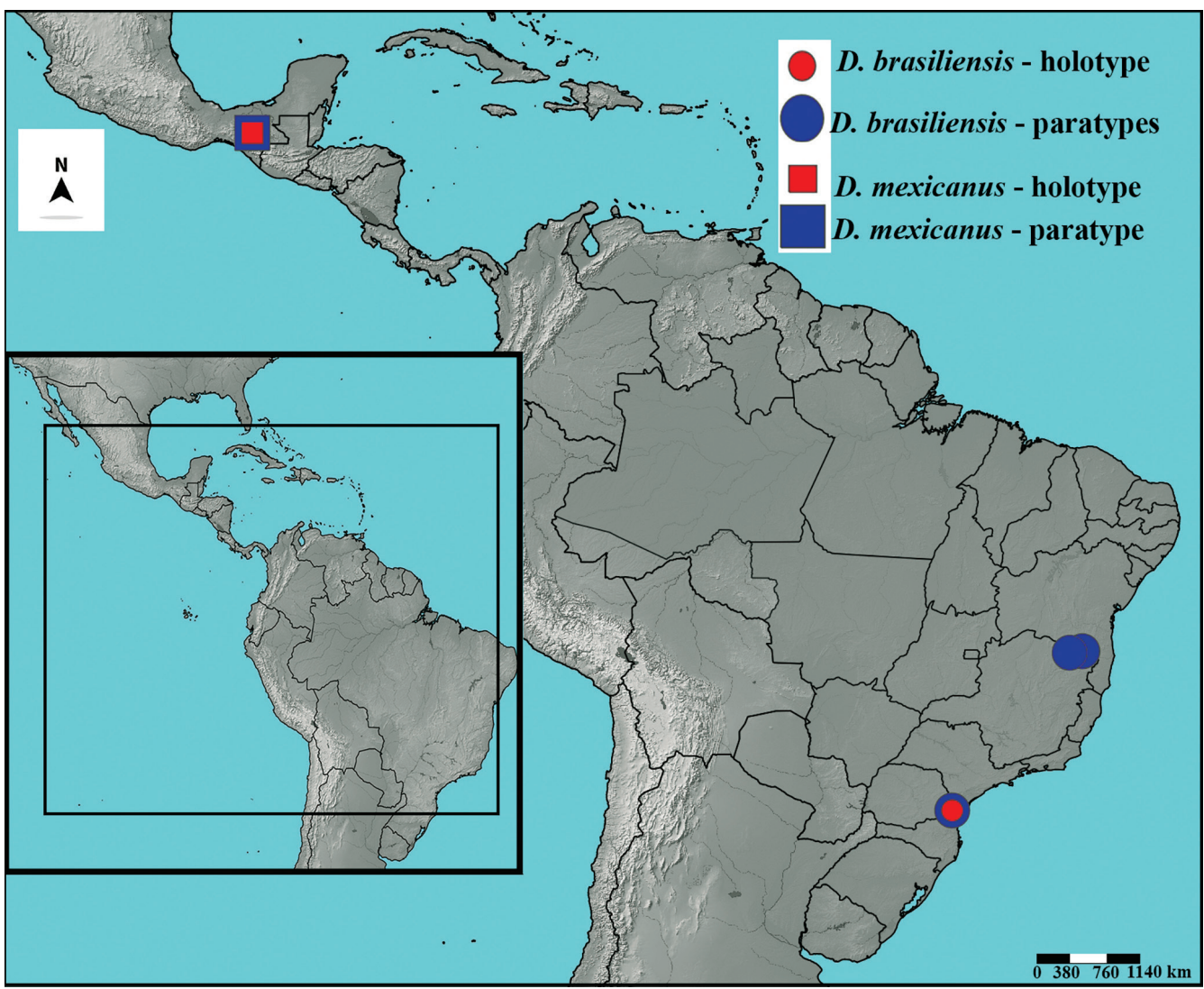

Figure 6. Geographic distribution of new species of Deinodryinus from the Neotropical region: Deinodryinus brasiliensis sp. nov.: red circle, holotype; blue circle, paratypes; Deinodryinus mexicanus sp. nov.: red squash, holotype; blue squash, paratype.

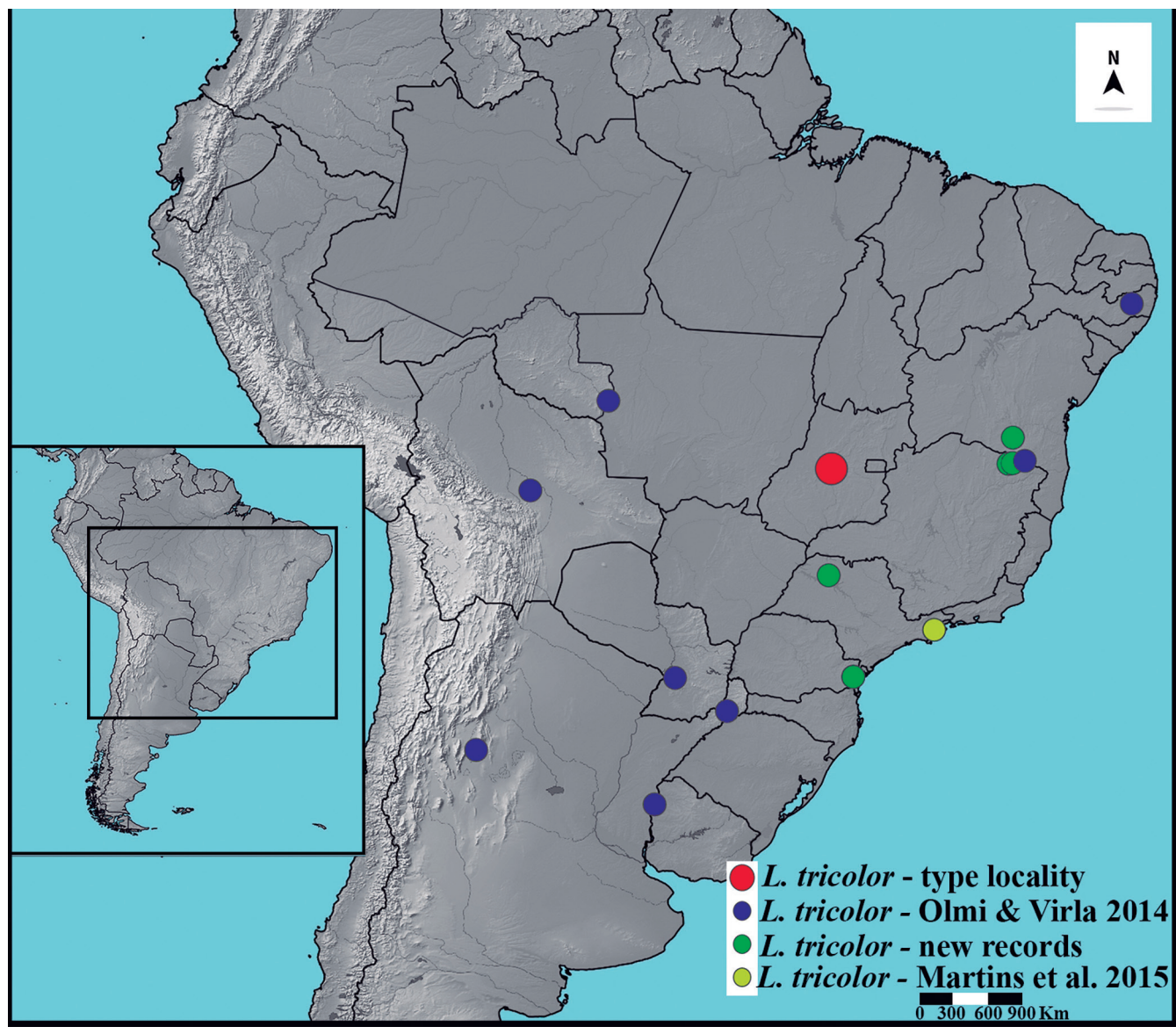

Figure 7. Geographic distribution of Lonchodryinus tricolor in the Neotropical region: red circle, type locality; blue circle, records presented by 0Imi \& Virla, 2014; green circle, new records; yellow circle, records presented by Martins et al., 2015. 
Etymology: The name mexicanus is a Latinized word meaning 'from Mexico', where this species has been collected.

Remarks: Among the species of Deinodryinus from the Neotropical region, $D$. mexicanus sp. nov. is similar to D. incaicus Olmi, 1984. They share region of head behind posterior ocelli without two oblique carinae connecting posterior ocelli to occipital carina; posterior surface of pronotum completely or almost completely smooth punctate, unsculptured among punctures; $5^{\text {th }}$ protarsomere apex with a set of lamellae, two of which are longer, and fore wing with two dark transverse bands.

Following the description of D. mexicanus sp. nov., the key to the females of the Neotropical Deinodryinus published by Olmi \& Virla (2014) should be modified by replacing couplet 73 as follows:

73. Region of head behind posterior ocelli without two oblique keels connecting posterior ocelli to occipital carina (Fig. $2 \mathrm{C}) ; 5^{\text {th }}$ protarsomere with one-two very long distal lamellae (Fig. 5C; and Fig. 59E in 0lmi \& Virla, 2014) . $.73^{\prime}$

- Region of head behind posterior ocelli with two complete or incomplete oblique keels connecting posterior ocelli to occipital carina; $5^{\text {th }}$ protarsomere without one-two very long distal lamellae (Plates 52E, $58 \mathrm{H}$ in Olmi \& Virla, 2014) 74

$73^{\prime} 5^{\text {th }}$ protarsomere with very long rows of lamellae, situated both in proximal and distal half (Fig. 59E in Olmi \& Virla, 2014)..D. incaicus Olmi.

- $5^{\text {th }}$ protarsomere with very short rows of lamellae situated only in the distal half (Figs. 3D, 5C) D. mexicanus sp. nov.

\section{Genus Lonchodryinus Kieffer, 1905 Lonchodryinus tricolor Kieffer, 1905 (Figs. 4A-F, 5A, B, 7)}

Lonchodryinus tricolor Kieffer, 1905: 96. Holotype female. Brazil, Goiás (MNHN, examined directly by $\mathrm{MO}$ and through photographs by ALM).

Comments: The studied specimens from Brazil studied here differs from the holotype in the following characters: The body length of female changes from 5.2-7.5 mm. Head with mandible (Fig. 4B) testaceous, except teeth dark brown; frons (Figs. 4B, D) rugose and punctate, vertex punctate, unsculptured among punctures; clypeus (Fig. 4B) rugose; gena rugose and partially punctate; frontal line complete. Pronotum (Fig. 4C) with central region smooth and lateral surfaces rugose and finely punctate; notauli incomplete (Figs. 4C, 5A) reaching approximately $0.9 \times$ length of mesoscutum (in holotype about 0.7); mesoscutellum (Fig. 4C) partially finely punctate; mesopleuron rugose and finely punctate; metapleuron rugose, punctate and with several transverse carinae. Ocellar ratio: $\mathrm{OL}=7, \mathrm{POL}=12, \mathrm{OOL}=11, \mathrm{OPL}=1, \mathrm{TL}=0$. Antenna filiform and not clavate. Antennomeres in following proportions: 35:11:50:39:25:18:16:15:20. Ratio of vein Rs: $2 r-r s=21$ and $3 R s \& 4 R s=43$. Protarsomeres in following proportions: $38: 6: 8: 36: 54 ; 5^{\text {th }}$ protarsomere with two rows of approximately 62 lamellae (in holotype about 57); distal apex with about seven lamellae (in holotype about nine). Claw of midle and posterior legs with basal expansion very development. Dorsal surface of propodeum as long as posterior surface (30:30).

Male: Unknown

Type material: Brazil: Holotype: + , BRAZIL: Goiás "Brésil" "Goyez" "Museum Paris\Collection\Ernest André \1914" "Dryinus\tricolor" "Type" "Lonchodryinus\tricolor Kieff" "O" “Kieffer det." "Muséum Paris\ EY 11379".

Additional material examined: Brazil, Bahia: 1 , Brazil, BA, Aracatu, $\backslash$ Faz. Lagoa do Tamburi, $\backslash 14.4619^{\circ} \mathrm{S}$ 41.4619 $\mathrm{W} \backslash$ 9-10.ii.2013, A. Ferreira \&\ M. França, Luminosa; 7 \%, same data, except 7-8.iii.2013; 6 \%, same data, except 8-9.v.2013; 2 \%, same data, except 6-7. vi.2013; 2 \%, same data, except 21-22.xii.2013 (UEFS). São Paulo: 1 \&, "Brasil, SP, Macaubal 25.vi.2007, $\backslash$ F.B. Noll, Malaise" “Dryinidae 020” (ZSJRP); 1 \%, Brasil, SP, São Luiz do Paraitinga, Parque Estadual Serra Mar - Núcleo Santa Virgínia, $23^{\circ} 19^{\prime} 17.9^{\prime \prime} \mathrm{S} / 45^{\circ} 05^{\prime} 42.9^{\prime \prime} \mathrm{W}$, Malaise trap, 21.XII.2010, N.W. Perioto et al., leg., (LRRP). Minas Gerais: 3 , "Brasil, MG, 10km a\SE de Berizal, Faz.\Veredão, $850 \mathrm{~m}, \backslash 15.665^{\circ} \mathrm{S} 41.666^{\circ} \mathrm{W} \backslash \backslash 11 . x i i .2012$, G. Melo" "Armadilha\luminosa" (DZUP); 1 \%, "Brasil, MG, 12km N। de Águas Vermelhas, $\backslash$ Faz. Faceiro, $845-850 \mathrm{~m}, \backslash 15.640^{\circ} \mathrm{S}$

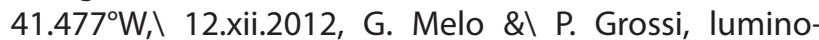
sa" (DZUP); 1 \%, same data, except 14.xii.2012 (DZUP). Paraná: 1 \&, "DEPTO ZOOL\ UF-PARANÁ" "Morretes Brasil \(IAPAR) 20. ii.1985 \C.I.I.F. (Luminosa) (DZUP); 1 q, "DEPTO ZOOL \UF-PARANÁ"“"Morretes-PR Brasil\(IAPAR)\ 13.iii.1985 C.I.I.F. (Luminosa) (DZUP).

Distribution: Lonchodryinus tricolor was previously known by females from Argentina, Bolivia, Brazil (Bahia, Goiás, Pernambuco, Rondônia and São Paulo) and Paraguay (Olmi \& Virla, 2014; Martins et al., 2015) (Fig. 7). Here we recorded also for the first time from the Brazilian states of Minas Gerais and Paraná. In addition, its distribution is extended to new localities in Bahia and São Paulo (Fig. 7).

Remarks: Lonchodryinus tricolor has wide distribution in different Brazilian ecosystems (Caatinga, Cerrado, and Atlantic Forest) suggesting that their hosts (probably Cicadellidae) are polyphagous and feed on different plants.

\section{ACKNOWLEDGMENTS}

We thank the Center of Electron Microscopy of Universidade Federal do Paraná (UFPR) for the SEM photomicrographs; Dr. Gabriel A.R. Melo (DZUP, curator of Hymenoptera) for providing the infrastructure needed to develop this study; CNPq (Conselho Nacional de Desenvolvimento Científico e Tecnológico) for fellowships provided to ALM (grant № 151827/2019-2). We 
are also grateful to all the curators sending on loan the material examined in this paper. Many thanks also to Dr. Claire Villemant (MNHN, Paris) for taking photos of the holotype of Lonchodryinus tricolor and two anonymous reviewers.

\section{AUTHORS' CONTRIBUTIONS}

A.L.M.: identified, described and redescribed the species, and revised the literature; took the photographs and prepared the figures; prepared the manuscript and review; ensured standardization and following of journal norms. M.O.: helped in the identifications, revised the literature, assisted in writing manuscript and review. All authors approved the final manuscript.

\section{DISCLOSURE STATEMENT}

No potential conflict of interest was reported by the authors.

\section{REFERENCES}

Brothers, D.J. 2011. A new late Cretaceous family of Hymenoptera, and phylogeny of the Plumariidae and Chrysidoidea (Aculeata). ZooKeys, 130(Special Issue): 515-542.

Guglielmino, A.; Olmi, M. \& Bückle, C. 2013. An updated host-parasite catalogue of world Dryinidae (Hymenoptera: Chrysidoidea). Zootaxa, 3740(1): 1-113.

Jurine, L. 1807. Nouvelle méthode de classer les Hyménoptères et les Diptères. Vol. 1. Hyménoptères. Genève, Paschoud. 326p., 14 pls.

Kieffer, J.J. 1905. Description de nouveaux Proctotrypides exotiques. Annales de la Sociétés scientifique de Bruxelles, 29: 95-142.
Kieffer, J.J. \& Marshall, T.A. 1905. Proctotrypidae. In: André, E. (Ed.). Species des Hyménoptères d'Europe et d'Algerie, 9. Paris, Hermann. p. 65-288.

Martins, A.; Lara, R.I.R. \& Perioto, N.W. 2015. New records of Dryinidae (Hymenoptera: Chrysidoidea) from the Atlantic Rainforest of São Paulo, Brazil. Pan-Pacifc Entomologist, 91(2): 196-199.

Martins, A.L. 2015. Anew species of Deinodryinus Perkins, 1907 (Hymenoptera, Dryinidae) from Minas Gerais, Brazil. Zootaxa, 4032(2): 236-240.

Martins, A.L.; Domahovski, A.C. \& Rendón-Mera, D.I. 2020. Sexual association and cicadellid hosts of Dryinidae (Hymenoptera, Chrysidoidea): description of five new species from Brazil and a synopsis of the interaction with Gyponini (Hemiptera, Membracoidea). Insect Systematics \& Evolution, 52(2):167-200.

Olmi, M. 1984. A revision of the Dryinidae (Hymenoptera). Memoirs of the American Entomological Institute, 37: 1913p.

Olmi, M. 1991["1989"]. Supplement to the revision of the world Dryinidae (Hymenoptera Chrysidoidea). Frustula Entomologica, 12: 109-395.

Olmi, M. \& Virla, E.G. 2014. Dryinidae of the Neotropical Region (Hymenoptera: Chrysidoidea). Zootaxa, 3792(1): 1-534.

Olmi, M.; Contarini, M.; Capradossi, L. \& Guglielmino, A. 2020a. Anteon hubeni a new species from Ecuador. Biodiversity Data Journal, 8: e56613.

Olmi, M.;Perkovsky, E.E.;Martynova, K.V.; Contarini,M.;Bückle, C.\&Guglielmino, A. 2020b. An important intermediate step in the evolution of pincer wasps: an extraordinary new type of chela from mid-Cretaceous Burmese amber (Hymenoptera, Dryinidae). Cretaceous Research, 111: 104420.

Olmi, M.; Copeland, R.S. \& van Noort, S. 2019. Dryinidae of the Afrotropical region (Hymenoptera, Chrysidoidea). Zootaxa, 4630(1): 1-619.

Perkins, R.C.L. 1907. Parasites of leaf-hoppers. Report of Work of the Experiment Station of the Hawaiian Sugar Planters Association, Division of Entomology. Bulletin, 4: 5-59.

Shorthouse, D.P. 2010. SimpleMappr, an online tool to produce publicationquality point maps. Available: https://www.simplemappr.net. Access: 09/01/2021.

Speranza, S.; Olmi, M.; Guglielmino, A.; Capradossi, L. \& Contarini, M. 2019. Discovery of the transantarctic distribution of the genus Metanteon Olmi (Hymenoptera: Dryinidae), with description of a new species from New Caledonia. Zootaxa, 4695(2): 189-194. 